\title{
Enunciación
}

http://revistas.udistrital.edu.co/ojs/index.php/enunc

DOI: http://dx.doi.org/10.14483/udistrital.jour.enunc.2015.2.a05

\section{¿Cómo leer libros voladores? Tres recomendaciones del Decálogo de la "buena lectura" audiovisual}

\author{
How to read flying books? Three recommendations of the Commandments of the \\ audiovisual "good reading"
}

\author{
Diana Patricia Romero Albaํ, Mauricio Alexánder Roa Gerena²
}

Para citar este artículo: Romero, D. P. y Roa, M. A. (2015). ¿Cómo leer libros voladores? Tres recomendaciones del Decálogo de la "buena lectura "audiovisual. Enunciación, 20(2), pp. 236-247.

Recibido: 23-mayo-2015 / Aprobado: 28-julio-2015

\section{Resumen}

Este artículo es resultado del trabajo de investigación desarrollado en la Maestría en Pedagogía de la Lengua Materna, de la Universidad Distrital Francisco José de Caldas. Su contenido presenta el esbozo de un modelo para leer de manera crítica y propositiva el film Los fantásticos libros voladores del señor Morris Lessmore. Luego de un rastreo teórico y a partir de los datos obtenidos en el proceso de investigación, se propone un decálogo de la "buena lectura del texto audiovisual", con el ánimo de plantear herramientas para entender los mensajes audiovisuales en la escuela. En esta contribución académica presentamos las tres primeras recomendaciones del Decálogo, en las que el lector puede cotejar la fuerza y magnitud de la investigación, cuya conclusión más cercana es que leer un texto audiovisual conserva múltiples rasgos de semejanza con la lectura literaria.

Palabras clave: texto fílmico, semiología, semiótica, studium, punctum.

\begin{abstract}
This article is the result of the research project carried out in the Mother Language Education Master's program, at Universidad Distrital Francisco José de Caldas. Its content presents the outline of a model to read the film The Fantastic Flying Books of Mr. Morris Lessmore in a critical and proactive way. After a theoretical research and based on the data obtained in the research process, a Decalogue of "good reading of the audiovisual text" is proposed, with the aim of raising tools to understand media messages in school. In this scholarly contribution we present the first three recommendations of the Decalogue, in which the reader can compare the strength and extent of the investigation. The nearest conclusion is that reading an audiovisual text retains many features of resemblance to the literary reading.
\end{abstract}

Keywords: film texts, semiotics, semiology, studium, punctum.

1 Profesora de lenguaje en la Institución Educativa Distrital (IED) INEM de Kennedy. Licenciada en lingüística y literatura, Universidad Distrital Francisco José de Caldas. Estudiante de Maestría en Pedagogía de la Lengua Materna, Universidad Distrital Francisco José de Caldas. Correo electrónico: alunanun@yahoo.con.mx

2 Formador de formadores a nivel nacional y tutor virtual en colaboración con la Universidad Nacional de Colombia y el Ministerio de Educación. Licenciado en lingüística y literatura, Universidad Distrital Francisco José de Caldas. Estudiante de Maestría en Pedagogía de la Lengua Materna, Universidad Distrital Francisco José de Caldas. Correo electrónico: mauricioroagerena@yahoo.com.mx 


\section{CLAQUETA}

Primer rollo, escena primera, toma número uno. Nos gustaría utilizar esta pizarra para recitar el contenido general de este trabajo. La hemos omitido a lo largo de todos los demás capítulos, pues nos parece innecesario para el gran público lector, para quien estos tecnicismos del montaje general pueden resultar irritantes. Antes de cada grabación de una película, es necesario que alguien "cante la claqueta", de forma que cuando se esté editando el material exista un registro permanente del orden cronológico de las diversas cintas. Preferimos contarle al lector acá lo que contiene todo el cuerpo de esta tesis de maestría, para no llenarlo de formas nemotécnicas que puedan perjudicar su gozo, en la continuidad que implica la relación entre la escritura y la lectura de textos cinematográficos y otros tantos textos, incluidos, desde luego, los literarios.

Se trata del esbozo de un modelo de lectura de textos fílmicos, al que hemos Ilegado luego de un arduo trabajo de investigación educativa. Pero también de una pieza viva, capaz de volar y de hacer volar otros organismos legibles. Por lo cual no podemos decir cómo leerlo. Presentamos acá un extracto del fuerte de la propuesta: el segundo capítulo (Decálogo de la "buena" lectura audiovisual): diez pasos, diez consejos, diez alternativas, incluso diez modelos contenidos en un modelo general de lectura de piezas audiovisuales en la escuela, desarrollado a partir de nuestra experiencia comprensiva de Los fantásticos libros voladores del señor Morris Lessmore (Joyce y Oldenburg, 2012) como maestros de lengua materna en Bogotá. Con todo, el lector es quien finalmente lo echará a rodar, le hará atravesar el firmamento. Dirige, junto con nosotros, cada escena. Su lectura cobra una especial importancia en los educadores de lengua materna, quienes podrán advertir en estos tres capítulos escogidos las posibilidades pedagógicas surgidas de estas recomendaciones sobre la escogencia, el análisis del sonido y la identificación de inconscientes cinematográficos del material audiovisual en la escuela. Son alternativas surgidas de la reflexión y la crítica magisterial ante las múltiples tribulaciones del quehacer docente, en tiempos de sobresaturación televisiva, virtual y audiovisual. Alternativas de lectura, alternativas didácticas, alternativas de vida. Por el momento, no podemos evitar la tentación: es un sitio común, un estereotipo. Pero a todos nos gusta. A todos nos fascina. Decir: "luces, cámara, acción".

\section{Tres recomendaciones del Decálogo de la "buena" lectura audiovisual}

\author{
Abordarás cada crítica como un pequeño \\ trabajo de creación.
}

Fernando Lara

\section{Primera recomendación: la línea y el punto}

Los fantásticos libros voladores del señor Morris Lessmore, de William Joyce y Brandon Oldenburg, cuenta la historia de un escritor que luego de ser arrastrado por un huracán, similar al Katrina, puede volar sin las limitaciones de la gravedad y sin la fricción del viento, convirtiéndose en lector. El video resultó ganador del Óscar a mejor animación en 2012 y abarca un récord impresionante de páginas en red que lo comentan, analizan, resumen e, incluso, cuelgan, para ser visto allí mismo: para el 30 de noviembre de 2015, el motor de búsqueda de Google arroja 37.400 registros asociados.

Luego de cerca de tres años de su primer estreno, es inestimable el creciente interés generado en las academias, en las escuelas y, en general, en todos los lectores, ilustradores, escritores, libreros, editores, músicos, estudiantes, maestros, bibliófilos y demás amantes de la cultura del libro. El así llamado "fenómeno Morris" es un elogio del universo "que otros Ilaman Biblioteca" (Borges, 2000), ese espacio tan parecido al paraíso, de infinitos anaqueles hexagonales, multiforme 
y ubicuo. Los libros ponen alas en cualquier joroba.

Morris causa cada vez mayor revuelo. Y también toda una revolución del cosmos que habita un libro: la editorial Alfaguara publicó en 2014 la versión literaria que Joyce le dedica a su mujer (q.e.p.d.), acompañada de las ilustraciones de Oldenburg. Esta publicación tiene una tradicional confección litográfica y, además, una compleja trama de vínculos entre el libro impreso, el libro virtual y el universo del cine.

El fantástico libro volador no se basa, sin embargo, en la película. Establece una mediación multimodal -término propio de nuestra era informática-: la animación se complementa con la versión impresa y la impresa con la fílmica, que es un homenaje al "cine mudo", por lo que puede decirse que resulta complementaria, alternativa, si se quiere, la presencia del texto literario. "Si bien la imagen, como cualquier otra, es una inducción a mirar -escribe Susan Sontag (2003, p. 17)-, el pie [la voz en off, en este caso; la "leyenda", en el otro] reitera, las más de las veces, la patente dificultad de hacerlo".

El libro es una invitación a mirar o, dicho de otra forma, ofrece una nueva mirada. Podemos interactuar con las secuencias, no solo devolviéndolas o adelantándolas, acercándolas, alejándolas, sino además ampliando su marco de referencia bidimensional o tridimensional -con la aplicación de realidad aumentada- a un marco hologramático. Una pieza fílmica adaptada para funcionar como un asombroso juguete posmoderno, como un videojuego que se despliega, literalmente, al abrir las hojas del libro. Un cuento corto, que, como todo lo bueno que hay en la efímera vida humana, quisiéramos contar mil veces.

Seguir todas sus señales, todas sus relaciones, sus vínculos, es un acto creativo. El caso del Señor Morris es una de esas piezas que motiva el análisis más minucioso, que no se blinda ni se acoraza, pero que al mismo tiempo cierra el espectro de su campo interpretativo. Encierra una gran carga significativa en pequeños detalles, casi como invitación a detener la secuencia, a ampliarla y empezar a reconocer las pistas inmersas en eso que han dado el llamar "lenguaje cinematográfico", que viene siendo algo así como el código de sus posibilidades. Pero cualquier analfabeta audiovisual puede ir descubriendo por sí mismo las riquezas técnicas, conceptuales y artísticas que hacen posible su vuelo. Al fin y al cabo, decía William Blake (1982), "la perfección está en el detalle".

Cada quien puede analizarlo a su manera. La nuestra ha terminado por convertirse en materia de investigación. Un huevo antropomórfico, "el libro [que] era un hombre amable", aparece en el momento en que el señor Morris Lessmore pierde sus esperanzas, su color, al contemplar los escombros que ha dejado el siniestro, "e insta a seguirlo". Desde entonces, no deja de acompañarlo. Lo despierta en la mañana, lo guía, lo orienta. Lo disciplina.

No sabía qué hacer ni qué camino tomar. Así que comenzó a vagar. Y vagar. Luego un poco de feliz casualidad llegó a sus manos. En lugar de mirar hacia abajo, como se había convertido en su hábito, el señor Morris Lessmore miró hacia arriba.

La forma en que mira, la forma en que piensa, la forma en que asume la existencia adquiere la imagen de Humpty Dumpty: el deseo de llegar a ser, la aspiración permanente del mejoramiento, de la transformación misteriosa que representa un huevo haciendo equilibrio frente al abismo. Entre las múltiples analogías que encontramos en este simbolismo, la más cercana no deja de ser la de la educación, aunque la analogía pueda aplicarse a muchos otros ámbitos.

"Cuando el Espíritu se desvanece, aparece la forma", escribe Bukowski (2014). Vivimos el ocaso del espíritu, un tiempo de extrema materialización de la vida en un mundo intercambiable por papeles, y como el papel puede quemarse, un mundo en destrucción. Los múltiples desastres naturales, las repercusiones de nuestras guerras 
y lo enfermizo de nuestros diversos sistemas (económico, social, cultural) remueven nuestro más íntimo sentido de resiliencia. No solo para sobreponernos al siniestro, a las múltiples tragedias de la cotidianidad, sino para modificar definitivamente nuestras maneras de vivir en el mundo.

Encontrar este texto audiovisual, esta pieza fílmica, este galardonado ejemplo del séptimo arte, ha orientado por completo este trabajo, porque nos ha demostrado que existe una buena forma de enseñar, desenmascarando todas aquellas pésimas estrategias y terribles "puestas en escena" que nos hacen perder "tiempo de estudio yendo a la escuela" (Shaw, 2012). Esa buena forma de enseñar es una versión ideal de una buena forma de aprender.

Resulta indispensable aprender a escoger el material fílmico que llevamos a la escuela.

Para explicar el modo en que llegó a nuestras manos esta feliz casualidad, nos referiremos a dos conceptos de la semiótica que Roland Barthes (1990) utiliza para hablar de la fotografía: el estudio (o studium) y el punto (o punctum). Estudiar la fotografía, dice, significa barrer con la mirada una serie de revelados, hasta encontrar una de tantas fotos, especialmente interesante por la forma en que punza. Hay un punto irritante, localizable en el plano de su composición. Es una transposición de los conceptos del Curso de Lingüística General, del ginebrino Ferdinand de Saussure (o de sus estudiantes): paradigma y sintagma. Con el primero se alude a las opciones de combinación de ciertos elementos lingüísticos; con el segundo, a las elecciones tomadas. Cine, vine y mine son opciones cuya arte combinatoria se localiza en la variación del primer elemento. Para hacer entendible la analogía, que se refiere a una forma estructural de entender los fenómenos del mundo, veamos algunos ejemplos. El menú en un restaurante representa el estudio o el paradigma de opciones, mientras que el plato que se solicita representa el sintagma. Se ha escogido debido a un punto en especial de su variación. Tal vez el tipo de carne, el tipo de ensalada o el postre. En el ajedrez hay un paradigma de jugadas posibles, pero, una vez movida una de las piezas del juego, se ha generado un sintagma, una nueva situación, un nuevo estado del juego (De Saussure, 1945 citado por Amar 2000). Solo con un movimiento puede haber jaque mate.

Parece un asunto sencillo, pero al trasponer estos conceptos al universo del cine, las opciones paradigmáticas, el estudio, abarca los más extensos listados de carteleras, programaciones, filmografías disponibles en internet, colecciones personales. Hay mucho que ver y muy poco que mirar.

Las propuestas pedagógicas que sugieren el uso de material audiovisual han representado un filtro indispensable, no solo por las recomendaciones para su buen uso, sino por el acierto de sus recomendaciones.

Con todo, no hay forma única de encontrar un buen film y en ocasiones ni el mejor método nos ayuda a evadir una mala elección en la sala de estrenos. En este caso, las líneas de investigación, los filtros de búsqueda, los materiales y herramientas de las bibliotecas y los salones coinciden en algo: para la enseñanza de la lengua materna resulta indispensable curar el quebrado puente entre las películas y los libros. Algunos eslóganes culturales como "apaga la televisión, prende un libro", "menos face y más book" encarnan una mirada apocalíptica de estos medios de comunicación. La nuestra es, en cambio, una mirada integrada, holística, aunque surja de cáscaras de huevo. Un buen video que nos inspira la lectura de otros videos, otros libros, otros textos es, siempre, una buena elección, un buen sintagma, un elemento indispensable.

La enseñanza de la lengua materna mediante el uso de material audiovisual: esa es la línea. El video de la lectura: ese es el punto. Un punto que proyecta nuevas líneas. Un punto en el que resulta útil -sobre todo- el consejo de Cavafis (1968): 
Cuando emprendas tu viaje a Ítaca pide que el camino sea largo, Ileno de aventuras, Ileno de experiencias. No temas a los lestrigones ni a los cíclopes ni al colérico Poseidón, seres tales jamás hallarás en tu camino,

si tu pensar es elevado, si selecta es la emoción que toca tu espíritu y tu cuerpo.

$\mathrm{Ni}$ a los lestrigones ni a los cíclopes ni al salvaje Poseidón encontrarás, si no los llevas dentro de tu alma, si no los yergue tu alma ante ti.

Ten siempre a Ítaca en tu mente. Llegar allí es tu destino.

Mas no apresures nunca el viaje.

\section{Segunda recomendación: el sonido}

Algunas veces la imagen sigue al sonido y representa un papel secundario y no viceversa. El sonido es algo más que una simple ilustración de lo que está sucediendo en la pantalla.

\section{Andrei Tarkovsky}

Así como hay, según Kant, un verdadero abismo de la razón que consiste en la petición de un fundamento último e incondicionado de todas las cosas, así también hay un verdadero abismo de la Acción, que consiste en la exigencia de una entrega total a la causa absoluta y concibe toda duda y toda crítica como traición o como agresión. (Zuleta, 1980, p. 2).

El imperativo categórico que indica el albur de buscar todas las razones en un único principio razonable, lleva a buscar un libro del que pudiesen surgir todas las demás obras. Hay quienes ponderan el Corpus Hermeticum o Kibalión (Trismegisto, 1998). Uno de los principios del Kibalión dice que "el universo es mente".

En el campo de la semiótica es común la alegoría que conlleva la pregunta: si un árbol se cae en medio del bosque y nadie lo escucha, ¿el árbol se cayó? Sin intérprete, la realidad significativa se quiebra. Los hechos objetivos dependen de los hechos mentales. Estos no dependen de nosotros: somos nosotros quienes nos inscribimos en la conciencia, pero el suceso puede llegar a nosotros o no. Peirce (1974) lo resume así: "el ser humano, en sí mismo, es un signo".

El segundo principio del Corpus dice que "el universo es ritmo". La teoría de las cuerdas y las realidades múltiples (Capra, 1983) concuerda en concebir una realidad originada por las vibraciones de una conciencia armoniosa. Estamos formados por átomos compuestos de vacío, se afirma, de modo que las partículas subatómicas más diminutas existen solo en la medida en que se desarrolla la composición de una partitura orquestal del orden de la realidad.

Lo que nos lleva a decir desde otra postura semiótica que el árbol, en efecto, se cayó. Una semiología musical nos lleva a pensar que, pese a todo, esta afectación en los ritmos propios del planeta, tan diminuta como el vuelo de una mariposa o tan sorda como la caída de un árbol solitario puede generar una tempestad, una ruptura o algún estrépito en el extremo opuesto de donde se origina, como la luz de esas estrellas muertas que aún nos Ilega en las noches más transparentes.

Sotto voce, forte subito, esforzando, mezzoforte, pianissimo. Una misma melodía que abre y cierra, con movimientos, variaciones, deformaciones. Punto de carencia, punto de ignición, punto de trascendencia (Goyes Narváez, 2008). Oscuro, claroscuro, tenue, muy tenue. Inicio, nudo, desenlace. Es el silbido característico del señor Morris Lessmore, en la primera escena; las notas que escucha al entrar en la biblioteca, provenientes de un piano, en otra; el entrenamiento de la alfabetización, la disciplina de la escritura, el sereno trabajo diario entre los anaqueles, el envejecimiento, el vuelo y revuelo del señor Morris, siempre acompañado de ese "hombre que era un libro", Humpty Dumpty. 


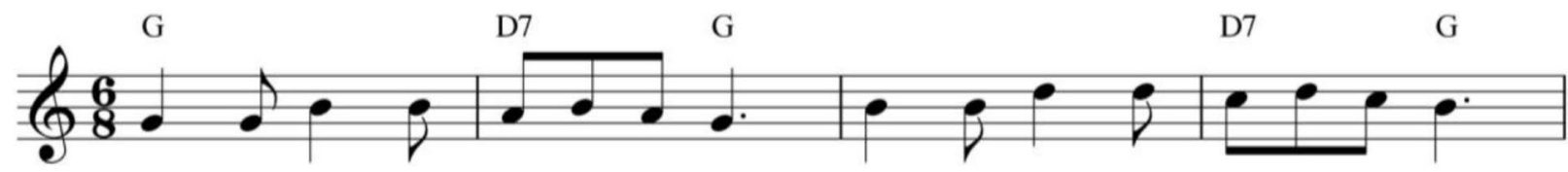

Hump - ty Dump - ty sat on the wall, Hump - ty Dump - ty had a great fall.

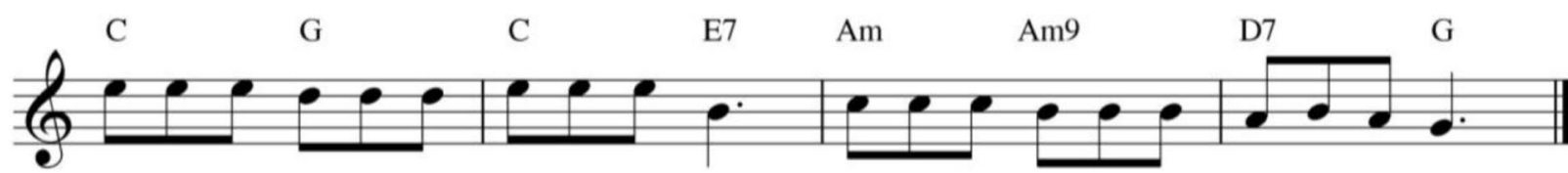

All the king's hor-ses and all the king's men could-n't put Hump-ty to - geth-er a-gain.

Figura 1. Partitura musical de Humpty Dumpty.

Fuente: http://kiboomukidssongs.com/humpty-dumpty-sheet-music/

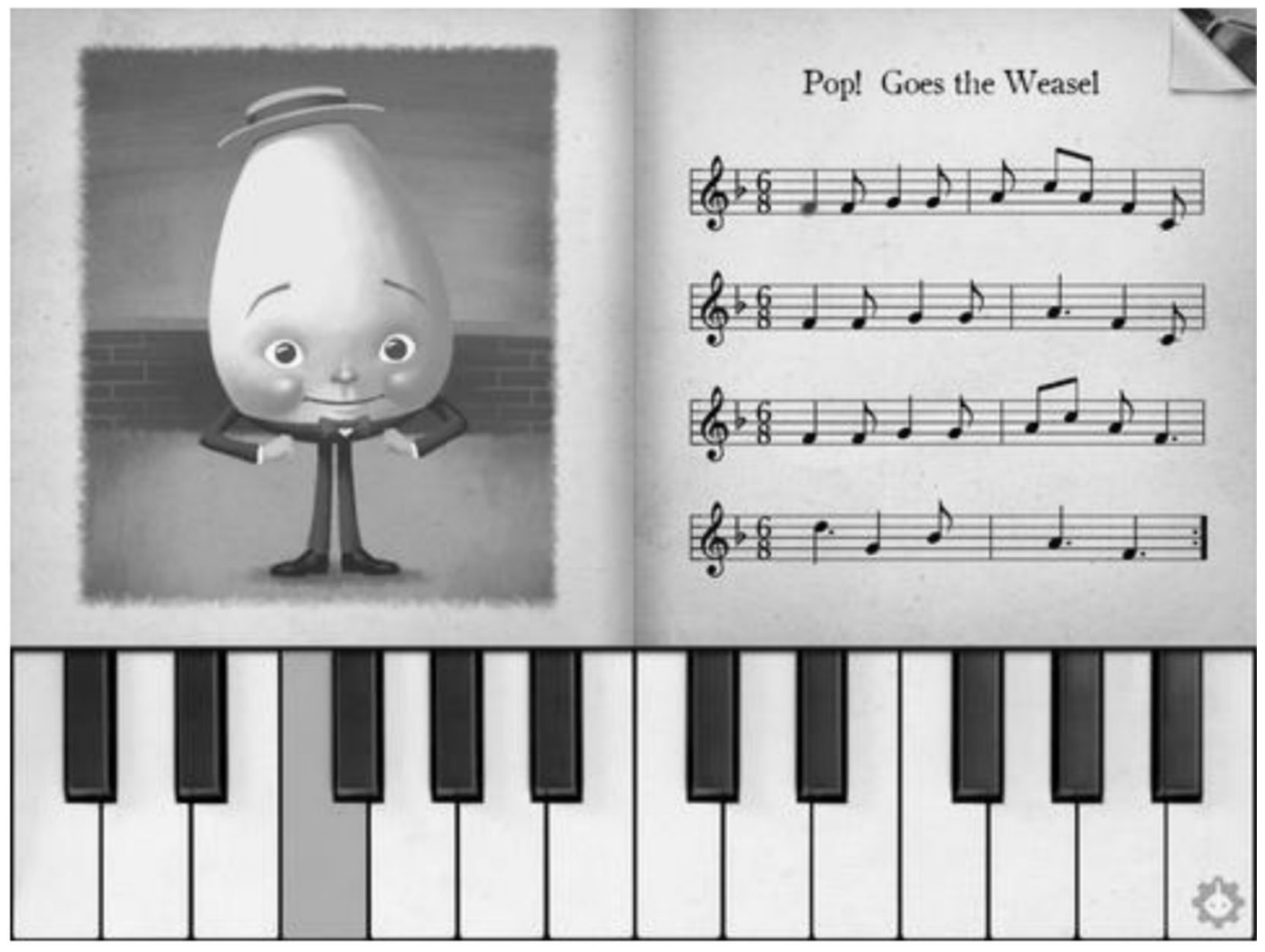

Figura 2. "Pop Goes the Weasel".

Fuente: Los fantásticos libros voladores del señor Lessmore Morris (Joyce y Oldenburg, 2012). 
"[..] Que era un libro". Al pasar y devolver las páginas se crea el efecto de movimiento dentro de la empastadura medio abierta de un volumen, creando el efecto de la animación, simulador de la realidad, a partir de láminas gráficas secuenciadas. Las hojas se recorren en las notas digitales de un piano.

Una de las características primordiales del video del señor Morris es la música de fondo. Es, casi, Como si la imagen surgiera del ensueño de la melodía.

Las mejores piezas del cine mudo acentuaban la selección musical. Hay una famosa anécdota de uno de los primeros cineastas de nuestro tiempo, Méliés: la presentación de un proyecto cinematográfico con una orquesta tocando en vivo y en directo, algo impensable hoy en día (Feldman, 1990, p. 27).

La primera lectura sugerida es de carácter musical. El señor Morris encuentra un instrumento musical abandonado y el siniestro parece superarse. Es el inicio de un nuevo camino, la felicidad de la bienvenida a este espacio habitado por la tradición, morir y resucitar para escuchar una melodía, una sola melodía, que solía utilizarse para vender helados. Aprender a interpretarla es una dulce entrada al juego de la alfabetización auditiva.

"Cállate y escucha las estrellas", dice Borges. "¿Cuántos sonidos puede tener el agua?", se preguntaba el director de cine ruso Andrei Tarkovsky (Feldman, 1990). La de Humpty Dumpty es una de esas melodías que vale la pena aprender a escuchar y a leer en todos sus matices, en todas sus versiones, en todas sus réplicas. Por ejemplo esta versión:

"Ni todos los caballos del rey, ni todos sus hombres

Pudieron traer mi corazón de vuelta

Todos los físicos

Y todos los matemáticos

Fracasaron en evitar que mi corazón se rompiera en dos."

\section{Tercera recomendación: la cámara de Gesell y el inconsciente fotográfico}

\section{El arte es un estado del alma. Marc Chagall}

Hay una broma que el multifacético artista Alejandro Jodorowsky (1997) utiliza cada vez que es invitado a brindar una charla sobre cine:

Un caballero sale con un pingüino a pasear por la calle. Un amigo que lo encuentra por casualidad ve esta extraña escena y asombrado le aconseja que lleve al pingüino a un zoológico. Tiempo después se reencuentran y aún el caballero camina con el pingüino a su lado. - $-i N o$ has Ilevado ese pingüino al zoológico?, le pregunta el amigo. —Sí — responde-. Ahora lo llevaré al cine".

La proyección del séptimo arte ha sido comparada con la proyección del inconsciente. Lo que Ilevamos, en últimas, a una sala de cine es nuestra extrañeza más íntima. Nuestro pingüino.

Para Jodorowsky, la escena de la córnea de un ojo abriéndose por la cortadura de una navaja de afeitar, mientras en el cielo una delgada nube desgarra la luna Ilena, de la película Perro andaluz (Buñuel, García Lorca y Dalí, 1929), se inscribe en la memoria del espectador con mayor acento que gran parte de toda la producción de la industria de Hollywood. No solo se refiere a una crítica del consumo de masas y de la industria cultural que genera productos basura, imposibles de recordar, sino una postura radicalmente psicoanalítica, o, como él mismo ha acuñado, psicomágica.

"El inconsciente acepta la metáfora" (Jodorowsky, 2007). Soñar no solo es un canal de desagüe de nuestras represiones cotidianas, de nuestros actos inconclusos, de nuestros deseos insatisfechos. También es una actividad cerebral, cognitiva y espiritual que procesa los registros de nuestra memoria más enigmática. El cine, entonces, implica un concepto propio de lo que Jung (2010) ha denominado "el inconsciente colectivo", la metáfora de lo que "todos soñamos". "No somos más que un desgarrón de las cosas" (Foucault, 1963, 1966, 2000),

(Anónimo) 
"delirios activos de la consciencia" (Artaud, Alonso y Abelenda, 1969), "simples criaturas hechas de sueños" (Yourcenar y Calatayud, 1989).

Hace poco, en el Museo de Arte de Buenos Aires, se dio a conocer un curioso montaje que relaciona el sueño y el cine. La obra es una videoinstalación compuesta de un sistema de múltiples pantallas en las que se proyecta un gran compendio de sueños de películas. Imágenes oníricas de diferentes épocas y lugares, desde Soñar, soñar, de Favio, hasta películas emblemáticas como Cuéntame tu vida, de Hitchcock, o Fresas salvajes, de Bergman. Los espectadores se sumergen en ese espacio, recorren y experimentan dentro de lo que podemos denominar como el inconsciente colectivo cinematográfico.

Lucas Tuturto (2010), en su corto de promoción de la videoinstalación, se pregunta: "Si las películas son sueños de la realidad, ¿los sueños de las películas qué son?". La respuesta resulta ser un sistema cíclico de múltiples pantallas proyectando sueños de películas, mientras el espectador se siente parte de la proyección, al estilo de la cámara Gesell. Verse a sí mismo de espaldas, repetido, distorsionado. Dentro de los recortes de los fragmentos más oníricos del cine.

Lo curioso de este proyecto curatorial o museológico es que las secuencias escogidas coinciden con cierto patrón. Las imágenes que se repiten en los fragmentos compilados, en realidad, se nutren del surrealismo que recoge Perro andaluz y sus réplicas y contrarréplicas que palpitan a lo largo del espacio y del tiempo. Inundaciones en espacios cerrados, incendios espontáneos como el de El espejo, de Andrei Tarkovsky (1975), los estallidos y fulminaciones y cataclismos de piezas como El club de la pelea (Fincher, 1999), Yo soy otro (Ocampo, 2008). Y muchos vuelos, míticos ícaros alados, brujas sobre escobas voladoras, caídas libres, casas y personajes en bicicleta pedaleando sobre las ráfagas arremolinadas de un huracán, como en el Mago de Oz. Todas estas piezas adicionales podrían formar parte de otra videoinstalación, y mostrarían más o menos lo mismo, crearían si no un mismo efecto, por lo menos una sensación similar.

El más pretérito símbolo en la genealogía del sueño es la levitación, la levedad absoluta, la pérdida del peso corporal, por vía controlada o por causa de fuerzas externas. Significa la ensoñación: "[...] la consciencia de que se está soñando" (Castaneda, 2000).

Hay una extensa relación entre el ensueño y la posición del espectador, que sabe que ha pagado por creer en un engaño. La comprensión de este fenómeno psicológico es el sustrato de la cámara de Gesell. Un ojo oculto que no participa, y, en cambio, está en posición de juzgar. Si bien es cierto que Freud, Lacan y Young concebían la escopofilia y el voyerismo como desviaciones libidinales tendientes al onanismo, el distanciamiento que hace el investigador de un criminal, viéndolo, literalmente, a través del espejo, sitio común ya en las películas policiacas, es el otro extremo de los usos tendenciosos.

La publicidad comercial desborda imágenes cuyo punctum asocia el producto en venta con cierto gesto densamente cargado de intención libidinal. Este simple distanciamiento mantiene en pie a diario la continuidad de empresas de todo tipo. "Si por un solo día dejan de publicitar a Coca-Cola -suelen decir comúnmente-, se caen las ventas, hasta la quiebra". La medicina, el psicoanálisis, la publicidad. El efecto Gesell, por Ilamarlo de algún modo, no es ajeno, tampoco, a los salones de clase.

Como todas las buenas ideas de la humanidad, esta inicialmente bienintencionada tentativa es utilizada en su propio detrimento. Buscaba ayudar a conocer el comportamiento de los niños en soledad, sin la interferencia de otro niño o adulto, en el campo propio del análisis del comportamiento dentro del mundo de la pediatría. Así como el descubrimiento de las propiedades atómicas y la teoría de la relatividad sirvieron para arrasar con ciudades enteras en cuestión de segundos, la cámara de Gesell ha servido en la escuela para convertir a los estudiantes en objetos observables, para 
que los docentes y directivos puedan saber cuándo son sinceros, cuándo mienten, cuándo ocultan algo y qué es lo que ocultan. El modelo de la escuela en que los maestros encarnan a vigilantes y los estudiantes interpretan a presuntos criminales es la degeneración más surreal de los usos pedagógicos de cuanto sabemos del inconsciente. Es el inconsciente colectivo de la relación entre la pantalla y la escuela. En lugar de las pantallas de aplicaciones pedagógicas, de software educativos, en lugar de plataformas de aprendizaje, en lugar de pantallas de televisor, de video beam o de los tradicionales proyectores de acetatos, en lugar de todas las pantallas informativas que pueden ayudar a transmitir la cultura a los estudiantes, la pantalla ha sido interpuesta. Ha dejado de un lado a los maestros y de otro a los estudiantes.

Los modelos tradicionales entrañan prácticas en las que, hasta cierto punto, ponen al maestro del lado del espectador encubierto. El estudiante es observado, adiestrado, evaluado, medido, lo mismo que los ratones del laboratorio del señor Skinner (1938), del otro lado del vidrio. Lo que ha impuesto la posmodernidad, la sociedad transparente, como dice Gianni Vattimo (1990), es poner al maestro del otro lado de la pantalla. El estudiante, desde su propio pupitre, puede grabar, publicar y poner en la palestra pública al maestro que tiene en frente suyo, con un celular sencillo. Puede comprobar la veracidad de los datos que nutren las didácticas al poder preguntarle a internet cualquier cosa en cualquier momento. Puede, si quiere, ponerle en ridículo o analizar su comportamiento.

Ese es, digamos, nuestro pingüino. Decidimos Ilevarlo a la sala de cine, para interrogarlo.

Leer el cine, como leer un sueño consiste, sobre todo, en encontrar el sentido oculto de sus símbolos más relevantes. La aparente fragmentación e incoherencia de los sueños, lo mismo que los inesperados giros y las imágenes que aparentemente nada tienen que ver con la trama de una película obedecen a principios contingentes, sin los cuales no se inscribiría con el mayor acento una imagen en la memoria.

Algunos hablan de la memoria fotográfica para referirse a la habilidad de reconocer un rostro. El punto en que radica la mayor carga significativa de film es lo que nosotros entendemos como el inconsciente fotográfico, lo que nos permite asociar de inmediato un título con una imagen en especial.

El motivo, la intención, la idea, se concentran en unas cuantas imágenes. En las películas de Woody Allen son comunes: la ubicación torcida de la cámara, un hombre huyendo de un seno gigante. En las películas de Oliver Stone -como Asesinos por naturaleza (1994) - son rostros ensangrentados, víboras fatales, escorpiones, dicho de otra forma, un ser humano salvaje, asesino como las bestias de la naturaleza.

Para encontrar el inconsciente fotográfico del Señor Morris, luego de proyectarlo en la escuela, nos hemos preguntado con nuestros estudiantes cuál es la imagen que más nos ha impactado de toda la pieza, la que no podemos olvidar.

"La del huracán" dicen algunos; "La de Morris volando", dicen otros. Pasamos revista a las imágenes del corto. $Y$ no hace falta hacer un sondeo ni soñar con esta imagen para determinar cuál es el inconsciente fotográfico. A lo largo de los quince minutos que dura el corto vemos todo como un sueño: ciclistas pedaleando a kilómetros del suelo, casas que dan vueltas en el horizonte y, luego, una mujer que levita, Ilevada por libros, libros capaces de volar, el señor Morris elevándose en el firmamento.

"El punto -según la geometría más popularsurge de la interceptación de dos líneas". Vemos al señor Morris volando en el huracán y resulta bastante impactante, nos hipnotiza, pero también nos impacta cuando aparece una dama voladora, arrastrada por libros y luego cuando el señor Morris también vuela, literalmente, rejuvenecido al finalizar. El punto radica en la oposición de estas dos linealidades, estas dos formas de avanzar en el vuelo. 


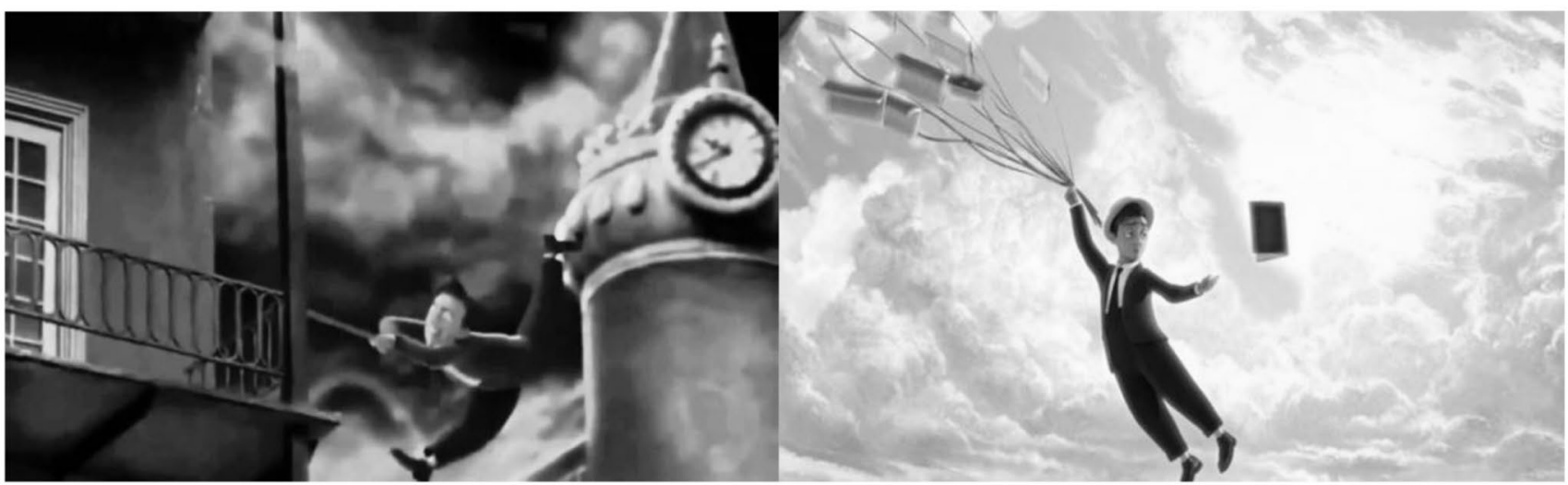

Figura 3. Contraste de dos "inconscientes fotográficos" en la película Los fantásticos libros voladores de señor Lessmore Morris.

Fuente: Joyce y Oldenburg (2012).

Mientras el huracán aparece, vemos a las personas y las cosas intentando no dejarse arrastrar por el siniestro, volando, hacia la derecha. En cambio, la linealidad del vuelo de los libros es hacia la izquierda: ¿Qué puede significar eso?

Si los sueños, como escribe Truman Capote, "son la mente del alma, nuestra verdad escondida" (1973, p. 33), el inconsciente fotográfico es la lógica de la película, el orden desconocido de ese caos de miles de imágenes de cada minuto de duración de una película.

Antes de lanzar una hipótesis sobre el significado de aquella lógica que la determina y que fija la magia (o psicomagia) de todo el film del Señor Morris, nos gustaría invitar al lector a observar por sí mismo, como en la cámara de Gesell, sin prejuicios, ni perturbaciones, la oposición direccional de estas dos manifestaciones del vuelo que constituyen, gracias a su iteración y reiteración, el inconsciente fotográfico.

Confíe en el graznido, en el trompeteo del pingüino que está a su lado. No olvide ese consejo.

\section{ALGUNAS CONCLUSIONES PARCIALES}

La modelación teórica corresponde a uno de los empeños menos comunes en el gremio magisterial. Es muy común que los maestros de las diversas áreas incursionen en el desarrollo de prácticas pedagógicas tendientes a corroborar las teorías pedagógicas, pero la formulación de nuevos postulados conceptuales y teóricos referentes a la enseñanza, en especial, de nuevos contenidos con nuevas plataformas de aprendizaje, en el área de lengua materna, ha significado la transformación del perfil del docente, no solo como un educador a secas, un profesor que, como dice Moreno (2009), "no hace más que profesar, ya que quisiera profetizar". En lugar de eso, ha generado profundidad y pertinencia al concebirse como un maestro-investigador, es decir, que en lugar de profetizar, construye, palmo a palmo, caminos hacia esa verdad que, para Nietzsche (2007), es "la mejor razón para morir", pero que para nosotros significa algo así como una razón más para otorgar sentido a la vida.

La verdad que puede transportar una pieza fílmica como la del Señor Morris. O tantas otras. Si resulta enriquecedor en algo este proceso analítico que hemos desplegado sobre este texto fílmico, es porque se han nutrido las voces de los múltiples teóricos que hemos ido rastreando en el curso de los años, en medio de nuestra dedicación en el ejercicio investigativo y magisterial, y también 
porque la mayoría de las hipótesis con mayor carga significativa ha surgido tanto de comentarios de estudiantes como del trabajo más riguroso en el aula de clase.

Lo que podemos concluir hasta el momento -pues esta es una investigación cuyos alcances a veces resultan difíciles de limitar- es que contar con una competencia audiovisual significa, sobre todo, contar con una competencia lectora.

Al establecer la analogía entre análisis de textos escritos y de textos audiovisuales, hemos comprendido que los contenidos propios del área de lengua materna no solo pueden movilizarse a partir del uso de material audiovisual como herramienta didáctica, sino que brindan el andamiaje propicio para analizar de la manera más juiciosa (y menos prejuiciosa) las piezas que se enriquecen cuando son llevadas a la escuela con las herramientas conceptuales y metodológicas que proponemos a lo largo de este tejido de palabras, imágenes y músicas.

No basta ser un verdadero amante del cine para escoger el material más importante que se debe llevar a la escuela. Hace falta también mantener una constante actualización, una permanente lectura, un rastreo incesante de los materiales que pueden ser compartidos con los estudiantes.

La codificación y categorización de elementos teóricos relacionados con el análisis de las piezas fílmicas nos ha sugerido que el estudio disciplinar de la lingüística y la literatura requieren una adaptación a lo que Valéry y Santos (1990) han denominado el color del tiempo, es decir, la actualización a las dinámicas de nuestra cotidianidad posmoderna y semivirtualizada. La tradición lingüística y literaria está Ilamada a contribuir en la comprensión de nuestro tiempo, tanto como contribuyó a concebir tantas otras épocas. Este simple muestreo nos ha inducido a pensar que nuestra formación no es un fósil de la antigua escuela, sino, al contrario, el soporte para renovar día tras día nuestra percepción nublada de nuestra era informática y teledirigida.
El resultado final, un esquema de análisis con altos niveles de abstracción del texto fílmico, que puede replicarse en otros textos audiovisuales y en otros contextos educativos, no es más que una provocación.

Se trata de recomendaciones sobre la lectura. Saber qué leer, cómo encontrar pistas entre líneas, cómo establecer relaciones intertextuales y cómo, incluso, limitar nuestra interpretación.

Puede ser esto importante para enriquecer la escritura de nuestros estudiantes. Pero la conclusión final es que usa todas las estrategias, moviliza todos los esfuerzos magisteriales para que, como Morris, volvamos a lo familiar, a lo fraternal, a la amistad reconfortante que nos trae un libro.

\section{REFERENCIAS}

Amar R., V. (2000). La alfabetización audiovisual a través de la educación con el cine. Comunicar, Revista Científica Iberoamericana de Comunicación y Educación, 15, 141-149.

Artaud, A.; Alonso, E. y Abelenda, F. (1969). El teatro y su doble. La Habana: Instituto del Libro.

Barthes, R. (1990). La cámara lúcida: nota sobre la fotografía. México: Paidós.

Blake, W. (1982). La poesía completa y prosa de William Blake. Barcelona: Ancla.

Borges, J.L. (2000). Nueva antología personal. Buenos Aires: Siglo XXI.

Bukowski, C. (2014). Fragmentos de un cuaderno manchado de vino. Barcelona: Anagrama.

Buñuel, L.; García Lorca, F. y Dalí, S. (1929). Perro andaluz. [Película]. Francia.

Capote, T. (1973). Miriam y otros relatos. Colección Zig Zag. Madrid: Rodas.

Capra, F. (1983). The turning point: Science, society, and the rising culture. Nueva York: Bantam.

Castaneda, C. (2000). Las enseñanzas de Don Juan: una forma yaqui de conocimiento. Madrid: Fondo de Cultura Económica.

Cavafis, C. (1968). Cien poemas. Traducción y notas de Francisco Rivera. Caracas: Monte Ávila. 
Feldman, S. (1990). El director de cine. Barcelona: Gedisa.

Fincher, D. (1999). El club de la pelea. [Película]. Basada en Club de lucha, de Chuck Palahniuk. Estados Unidos: Fox.

Fleming, V. (1929). El mago de Oz. [Película]. Estados Unidos: Metro Goldwyn Mayer.

Foucault, M. (1963). El nacimiento de la clínica. Una arqueología de la mirada médica. México: Siglo XXI.

Foucault, M. (1966). Las palabras y las cosas: una arqueología de las ciencias humanas. Buenos Aires: Siglo XXI.

Foucault, M. (2000). Nietzsche, la genealogía, la historia. Valencia: Pre-Textos.

Goyes Narváez, J.C. (2008). El relato simbólico en "Stand by Me", de Rob Reiner; "El espejo", de Tarkovski, y "Paisaje en la niebla", de Angelopoulos. Tesis doctoral. Madrid: Facultad de Ciencias de la Información, Universidad Complutense de Madrid.

Jodorowsky, A. (1997). La sabiduría de los chistes. Ensayo con ilustraciones de George Bess. Barcelona: Obelisco.

Jodorowsky, A. (2007). Los Evangelios para sanar. Ensayo. Madrid: Siruela.

Joyce, W y Oldenburg, B. (2012). Los fantásticos libros del señor Morris Lessmore. [Video]. Recuperado de: https://www.youtube.com/watch?v=qgY4Xg4k_-o

Jung, G. (2010). Obra completa. Los arquetipos y lo inconsciente colectivo. Volumen 9/1. Traduccion Carmen Gauger. Madrid: Editorial Trotta.

Moreno, J. (2009). Educar para pensar. Pensar para crear. Crear para aprender. Recuperado de: www. signumaulaabierta.blogspot.com.
Nietzsche, F. (2007). El Anticristo. Maldición sobre el cristianismo. Barcelona: Alianza.

Ocampo, O. (2008).Yo soy otro. [Película]. The Eyed Films. Colombia.

Peirce, C.S. (1974). Collected papers of Charles Sanders Peirce. Vol. 5. Massachusetts: Harvard University Press.

Shaw, G.B. (2012). Pygmalion. Berlín: Simon and Schuster.

Skinner, B.F. (1938). El comportamiento de los organismos: un análisis experimental. Barcelona: Fontanella.

Sontag, S. (2003). Ante el dolor de los demás. Madrid: Alfaguara.

Stone, O. (1994). Asesinos por naturaleza. [Película]. Estados Unidos: Warner Bross.

Trismegisto, H. (1998). Corpus Hermeticum: y otros textos apócrifos. Vol. 39. Madrid: Edaf.

Tarkovsky, A. (1975). El espejo. [Película]. Unión Soviética.

Tuturto, L (2010). El inconsciente cinematográfico. [Video]. Recuperado de: https://vimeo. com/99429302.

Valéry, P. y Santos, C. (1990). Teoría poética y estética. Madrid: Visor.

Vattimo, G. (1990). La sociedad transparente. Barcelona: Paidós.

Yourcenar, M. y Calatayud, E. (1989). El tiempo, gran escultor. Madrid: Alfaguara.

Zuleta, E. (1980). Elogio de la dificultad y otros ensayos. Madrid: Ariel. 